\title{
Disposition of cimicoxib in plasma and milk of whelping bitches and in their puppies
}

\author{
M. Schneider ${ }^{1 *}$, A. Kuchta ${ }^{2}$, F. Dron ${ }^{1}$ and F. Woehrlé
}

\begin{abstract}
Background: Caesarean section of bitches is a well recognized painful condition in dogs and it can be classified as a soft tissue surgery. Cimicoxib, a newly registered NSAID in European Union has a claim for the relief of pain in peri-operative conditions. However, in case of caesarean section, the main concerns of using NSAIDs are the transfer of the drugs into milk and its impact on the suckling pups. Thus, the aim of the present work was to evaluate the transfer of cimicoxib into the milk of 6 lactating bitches after a single oral administration of the drug on day 0 (just after whelping) and on day 28 at the target dose of $2 \mathrm{mg} / \mathrm{kg}$. Another aim of the study was to evaluate the transfer of the drug from the milk into the suckling pups. Blood and milk samples were collected from the bitches after each administration on day 0 and day 28 and blood samples were drawn from the pups after suckling on day 28.

Results: All bitches whelped without any complication and gave birth to 38 pups. After administration on D0, the mean observed plasma $C_{\max }$ in bitches was $0.5323 \mu \mathrm{g} / \mathrm{mL}$ and the mean area under the concentration-time curve extrapolated to the infinity, $A \cup C_{\mathbb{N F}}$, was $2.411 \mu \mathrm{g} . \mathrm{h} / \mathrm{mL}$. After administration on D28, only AUC $\mathrm{INF}_{\mathrm{NF}}$ was significantly higher with a value of $3.747 \mu \mathrm{g} . \mathrm{h} / \mathrm{mL}$. In milk, after administration on D0, the mean observed $\mathrm{C}_{\max }$ was $0.9974 \mu \mathrm{g} / \mathrm{mL}$

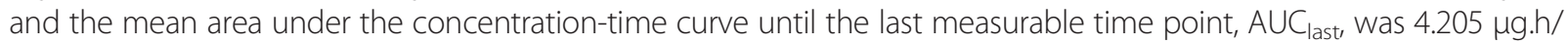
$\mathrm{mL}$. Out of 24 sampled pups on D28, only 2 animals had a sample with very low cimicoxib concentrations slightly above the limit of quantification $(0.01 \mu \mathrm{g} / \mathrm{mL})$.
\end{abstract}

Conclusion: The presented data show that cimicoxib given by oral route to lactating bitches at a single dose of $2 \mathrm{mg} /$ $\mathrm{kg}$ had a high transfer rate into the milk with a milk to plasma ratio of 1.7 to 1.9. The transfer rate to the suckling pups was low and no clinical abnormalities were detected in both bitches and pups.

\section{Background}

Caesarean section of bitches is a well recognized painful condition in dogs [1]. It can be classified as a soft tissue surgery like ovariohysterectomy. In order to relief pain in peri-operative conditions, NSAIDs proved to be much helpful. Several NSAIDs are approved for the treatment of peri-operative pain in dogs and cimicoxib, a newly registered drug in European Union, has such a claim. However, in case of caesarean section, treatment of postoperative pain with NSAIDs is not a common practice. The main concerns of using NSAIDs are the transfer of the drugs into milk and its impact on the suckling pups [1]. At present, studies evaluating the transfer of NSAIDs into the milk of bitches are not published. The

\footnotetext{
* Correspondence: marc.schneider@vetoquinol.com

'Vétoquinol Global Development, 70200 Lure, France

Full list of author information is available at the end of the article
}

excretion of NSAIDs into milk was essentially studied in dairy cows in order to calculate withdrawal periods for a consumer protection purpose [2-5]. The excretion rates of these drugs into milk are generally quite low [2-5]. However, excretion of selective COX-2 inhibitors (coxib) in dairy milk is not described as these drugs are not yet approved in food animals. Coxibs being more lipophilic than classical NSAIDs [6], their excretion rate into milk might be higher.

In human medicine, NSAIDs are regularly used for the treatment of post-operative pain after elective or unscheduled caesarean section [7-11]. Use of these drugs is associated with faster recovery and lower requirements of opioid drugs [12-16]. The excretion of coxibs into human milk was studied with parecoxib [17]. The obtained milk concentrations of parecoxib and its active metabolite valdecoxib were quite low resulting in low 
exposure rates of the suckling children. The authors concluded that the administration of parecoxib to lactating women after cesarean delivery is unlikely to cause adverse effects in breastfed infants.

Thus, the main aim of the present study was to provide some information regarding the transfer of cimicoxib into the milk of bitches for the potential use of the drug in post-caesarean pain relief. The second aim of the study was to evaluate the transfer of the drug from the milk into the suckling pups.

\section{Results}

All 6 bitches whelped without any complication and gave birth to 38 pups. The bitches were dosed successfully on study day 0 and 28 with no post-dosing vomiting. All bitches lost weight (range of weight loss was $0.5-3.8 \mathrm{~kg}$ ) from study day 0 until study day 29. A decrease in bodyweight is not unexpected with lactating bitches. All pups were still alive on day 7 and they gained bodyweight from study day $7 / 8$ to study day 29. On day 19, one pup was missing and was presumed to have been eaten by its mother. For all other pups, no abnormalities were detected during the scheduled veterinary examinations or clinical assessments. Cimicoxib was well tolerated in the bitches and in the pups throughout the study.

Mean concentration-time profiles of cimicoxib in plasma and in milk of the bitches are presented in Fig. 1. After administration on D0, the mean observed plasma $\mathrm{C}_{\max }$ was $0.5323 \mu \mathrm{g} / \mathrm{mL}(\mathrm{sd}=0.08694 \mu \mathrm{g} / \mathrm{mL})$ and the mean observed occurrence time of the $C_{\max }, T_{\max }$, was
$2.83 \mathrm{~h}(\mathrm{sd}=1.33 \mathrm{~h})$. The mean terminal half-life, $\mathrm{T}_{1 / 2 \lambda \mathrm{z}}$, was $1.47 \mathrm{~h}(\mathrm{sd}=0.31 \mathrm{~h})$. The mean area under the concentration-time curve extrapolated to the infinity, $\mathrm{AUC}_{\text {INE }}$ was $2.411 \mu \mathrm{g} . \mathrm{h} / \mathrm{mL}(\mathrm{sd}=0.9771 \mu \mathrm{g} . \mathrm{h} / \mathrm{mL})$. The extrapolated part was low with a mean value of $3.14 \%$ (sd $=1.41 \%)$. The total clearance, Cl_F, was $0.8896 \mathrm{~L} /$ h.kg (sd $=0.2575 \mathrm{~L} / \mathrm{h} . \mathrm{kg})$. The mean residence time extrapolated to the infinity, $\mathrm{MRT}_{\mathrm{INE}}$, led to a mean value of $4.11 \mathrm{~h}(\mathrm{sd}=1.48 \mathrm{~h})$. After administration on D28, the mean observed $C_{\max }$ was $0.6692 \mu \mathrm{g} / \mathrm{mL}$ (sd $=0.3088 \mu \mathrm{g} /$ $\mathrm{mL}$ ) which was not statistically higher than after administration on D0. The mean observed $\mathrm{T}_{\max }$ was $2.67 \mathrm{~h}$ $(\mathrm{sd}=1.03 \mathrm{~h})$ which was close to the value obtained on D0 and not statistically different. The mean terminal half-life, $T_{1 / 2 \lambda}$, was $2.15 \mathrm{~h}(\mathrm{sd}=0.59 \mathrm{~h})$ which was somewhat longer than after administration on D0, but the difference was not statistically significant. The mean $\mathrm{AUC}_{\mathrm{INF}}$ was $3.747 \mu \mathrm{g} . \mathrm{h} / \mathrm{mL}(\mathrm{sd}=1.821 \mu \mathrm{g} . \mathrm{h} / \mathrm{mL})$. The extrapolated part was still low with a mean value of $4.22 \%(\mathrm{sd}=3.05 \%)$. The $\mathrm{AUC}_{\mathrm{INF}}$ value was statistically higher $(p=0.039)$ than the mean value obtained on D0. The total clearance, Cl_F, was 0.5867 L/h.kg (sd= $0.1472 \mathrm{~L} / \mathrm{h} . \mathrm{kg})$ and was statistically lower $(p=0.031)$ than the clearance calculated on D0. The mean MRT $\mathrm{INF}_{\mathrm{I}}$ was $5.15 \mathrm{~h}(\mathrm{sd}=1.39 \mathrm{~h})$.

In milk, after administration on D0, the mean observed $C_{\max }$ was $0.9974 \mu \mathrm{g} / \mathrm{mL}(\mathrm{sd}=0.250 \mu \mathrm{g} / \mathrm{mL})$ which was about twice the value obtained in plasma on D0. The mean $\mathrm{T}_{\max }$, was $3.17 \mathrm{~h}(\mathrm{sd}=1.33 \mathrm{~h})$. The mean area under the concentration-time curve until the last measurable time point, $\mathrm{AUC}_{\text {last }}$, was $4.205 \mu \mathrm{g} . \mathrm{h} / \mathrm{mL}(\mathrm{sd}=$

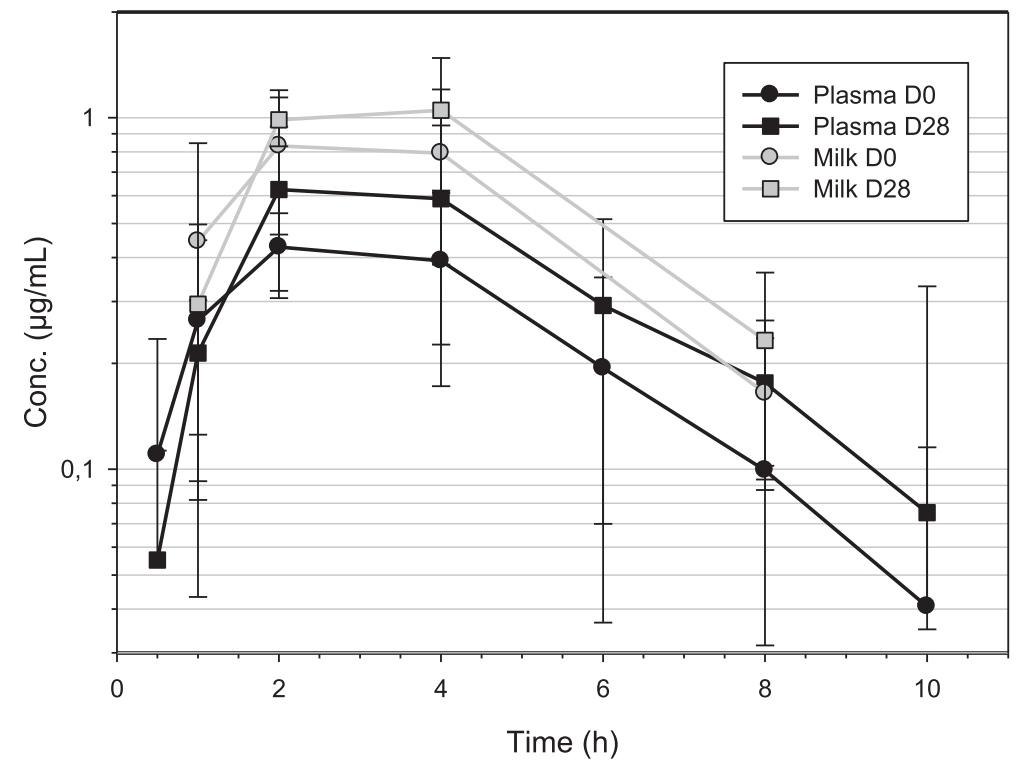

Fig. 1 Mean concentration-time profiles of cimicoxib (semi-logarithmic scale) in plasma and milk of 6 bitches after a single oral tablet administration of a dose of $2 \mathrm{mg} / \mathrm{kg}$ (range 1.4 to $2.6 \mathrm{mg} / \mathrm{kg}$ ) given just after whelping (D0) and 28 days later (D28). On D28, the milk concentration corresponds to the average out of 6 values for the time point of $1 \mathrm{~h}$, out of 5 values for the time points of 2 and $4 \mathrm{~h}$ and out of 3 values for the time point of $8 \mathrm{~h}$ 
$1.534 \mu \mathrm{g} . \mathrm{h} / \mathrm{mL})$. This value was also about twice the value obtained in plasma on D0. The mean residence time until the last measurable time point, $\mathrm{MRT}_{\text {last }}$ was $3.25 \mathrm{~h}(\mathrm{sd}=0.85 \mathrm{~h})$. After administration on D28, milk samples could not be collected at every time point for all bitches because they produced much less milk than on D0. As the missing time points were located in the last elimination phase, only the observed $C_{\max }$ and the $T_{\max }$ could be obtained in the milk samples. The mean observed $\mathrm{C}_{\max }$ was $1.146 \mu \mathrm{g} / \mathrm{mL}(\mathrm{sd}=0.2683 \mu \mathrm{g} / \mathrm{mL})$ and the mean observed $\mathrm{T}_{\max }$ was $3.00 \mathrm{~h}(\mathrm{sd}=1.10 \mathrm{~h})$ which was close to the value obtained on D0.

For the pups, the time lapse between suckling and the first blood collection time point ( $1.5 \mathrm{~h}$ post bitch dosing) ranged from 20 to $29 \mathrm{~min}$. Out of 24 sampled pups, only 2 animals had a plasma sample with very low cimicoxib concentrations, slightly above the limit of quantification. Both samples were taken 8.5 and $24 \mathrm{~h}$ after dosing the bitch. In the plasma samples of all the other puppies, the concentration of cimicoxib remained below the limit of quantification. Thus, although cimicoxib reached high concentrations in the milk of the bitches, the amount taken and/or absorbed by the pups is quite low.

\section{Discussion}

To the best of our knowledge, this is the first report on excretion of NSAIDs into dog milk and on subsequent concentrations reached in suckling pups. Pharmacokinetics of cimicoxib were also described in other monogastric species: horses [18] and donkeys [19]. Compared to published pharmacokinetic data in dogs [20], the bitches in the present study could seem extensive metabolising animals. Indeed, the obtained terminal half-lives in plasma for days 0 and 28 were within a range of 1.09 to $2.97 \mathrm{~h}$, whereas the mean terminal half-life in "poor metabolizers" was $8.0 \pm 0.6 \mathrm{~h}$ [20]. The obtained mean terminal half-live on D0 (1.47 h) was even somewhat lower than the published value $(2.9 \mathrm{~h})$. The mean value obtained on D28 $(2.15 \mathrm{~h})$ was closer to the published value. Terminal halflife is a hybrid parameter depending both on volumes of distribution and on total body clearance. Lactation is known to modify both parameters with an increase in volume of distribution and/or an increase in clearance [21]. However, the most often encountered situation is an increase in total body clearance during early lactation [22] and hence a decrease in terminal half-life of drugs. This latter situation seems to be the case in our study on D0 because the mean clearance obtained, $0.8896 \mathrm{~L} / \mathrm{h} . \mathrm{kg}$, is about two times higher than the clearance of non lactating dogs, 0.4959 L/h.kg [23]. At a later lactation stage on D28, the terminal half-life was increased almost significantly ( $p$ $=0.067$ ) while $\mathrm{AUC}_{\mathrm{INF}}$ values were also significantly increased $(p=0.039)$. This increase of exposure to cimicoxib may be explained only by a decrease of the total body clearance confirming that the shorter terminal half-life at early lactation was the result of an increased clearance on D0. The $C_{\max }$ and $T_{\max }$ values obtained in whelping bitches in the present study on D0 were close to published values in "normal" beagle dogs [23]. However, terminal half-life and $\mathrm{AUC}_{\mathrm{INF}}$ values were lower in the present study which reinforces the clearance hypothesis.

The measured concentrations of cimicoxib in the bitch milk are higher than the concentrations measured in plasma leading to quite high milk to plasma concentration ratios of 1.7 to 1.9 . Thus, cimicoxib seemed to be concentrated in the milk contrary to what was observed for parecoxib in human medicine [17]. This behaviour difference between the two drugs may be explained by the lipophilic nature of the drugs and by the milk composition. Dog milk contains about $10 \%$ fat [24] whereas human milk contains about 3 to $5 \%$ fat $[25,26]$. The higher fat content of dog milk may increase the transfer rate of lipophilic drugs relative to human milk. Therefore, it might explain why the obtained milk to plasma concentrations ratio of cimicoxib in dog milk was higher than the ratio obtained with parecoxib in human milk. Concerning parecoxib, the volume of distribution of the drug in the dog was about $0.09 \mathrm{~L} / \mathrm{kg}$ [27] which reflects a distribution essentially within body water. Its main active metabolite, valdecoxib, has a volume of distribution of about $0.9 \mathrm{~L} / \mathrm{kg}$ [28] which is 10 times higher than its prodrug but still lower than the volume of distribution of cimicoxib which is about $1.1 \mathrm{~L} / \mathrm{kg}$ [20]. As the volume of distribution of parecoxib is lower than the volume of distribution of cimicoxib, its transfer rate into the milk should be lower [21].

Despite these high milk to plasma concentration ratios, the intake of cimicoxib by the puppies seems to be very low. Indeed, cimicoxib concentration in the pups on D28 was below or slightly above the lower limit of quantification $(0.01 \mu \mathrm{g} / \mathrm{mL})$. In order to evaluate the dose of cimicoxib taken by the pups, a worst case scenario was considered. The $\mathrm{C}_{\max }$ of cimicoxib in milk on D28 $(1.146 \mu \mathrm{g} / \mathrm{mL})$ was taken together with the average milk intake of the puppies. In the present study, this value was not measured; however, Oftedal [24] evaluated a mean milk intake of $175 \mathrm{~g}$ in 26 days old beagle puppies. Thus, as age of the puppies was very close to the age of the puppies in our study (28 days), this intake value was taken as a basis for our evaluation. Subsequently, the mean intake was calculated to be $201 \mu \mathrm{g}$ of cimicoxib, assuming that the density of dog milk is close to 1 . The mean weight of the pups in our study was $1.11 \mathrm{~kg}(\mathrm{sd}=0.23 \mathrm{~kg})$ which is close to the weight of the pups in the manuscript of Oftedal [24]. The maximal cimicoxib dose taken by the pups was $0.18 \mathrm{mg} / \mathrm{kg}$ which is about 10 times lower than the dose administered to the bitches. Pups were not weighed on D0 in our study 
and therefore, estimation of the dose of cimicoxib taken after suckling is not straightforward. However, based on literature data $[24,29]$ a weight of $0.239 \mathrm{~kg}$ and a mean milk intake of about $100 \mathrm{~g}$ may be considered. Taking into account the $\mathrm{C}_{\max }$ of cimicoxib in milk on D0, $0.9974 \mu \mathrm{g} / \mathrm{mL}$, a maximal dose of about $0.42 \mathrm{mg} / \mathrm{kg}$ can be estimated. This dose is higher than the dose taken on D28, but it remained quite low.

\section{Conclusion}

The presented data show that cimicoxib given by oral route to lactating bitches at a dose of $2 \mathrm{mg} / \mathrm{kg}$ had a high transfer rate into the milk with a milk to plasma ratio of 1.7 to 1.9 . Twenty eight days old puppies suckling the milk from the dams treated with this single $2 \mathrm{mg} / \mathrm{kg}$ oral dose had plasma cimicoxib concentrations below or very close to the limit of quantification $(0.01 \mu \mathrm{g} / \mathrm{mL})$. Thus, the data obtained in the present work suggests that after administration of a single clinical dose of cimicoxib to whelping bitches, suckling puppies should be minimally exposed to the drug through the dam's milk and no serious adverse effect should occur.

\section{Methods}

\section{Animals and housing}

Cimicoxib was given to 6 bitches shortly after whelping (D0) and the transfer of the drug into the milk of the dams was evaluated. The treatment was repeated about one month after whelping (D28) and the disposition of cimicoxib was evaluated again in the bitches as well as in their pups after suckling. The general study design is described in Table 1 and was approved by the Charles River Laboratories Preclinical Services Ireland Ethical Committee which has the authorization number AE19108.

Six Beagle bitches from the breeding colony of Charles River Laboratories Preclinical Services at a late pregnancy stage weighing 10.8 to $18.7 \mathrm{~kg}$ were used and they were about 5 to 8 years old. Each bitch was enrolled onto the study when she gave birth to pups. Bitches were housed individually in pens measuring $4.0 \mathrm{~m} \mathrm{x}$ $1.1 \mathrm{~m}(\mathrm{l} \mathrm{x} \mathrm{w})$. Inside each pen, a resting area with rubber matting was provided for each bitch. The pen was divided into two sections by a division down the middle.
The dividing section had a gate to allow the animal access to both halves of the pen. The gate was used to separate the bitch from her pups when necessary. In each pen there was a whelping box measuring approximately $1.1 \mathrm{~m} \times 0.7 \mathrm{~m}(\mathrm{l} \mathrm{x} \mathrm{w})$. An infra-red lamp was added at the time of whelping to provide a supplementary source of heat. After whelping, each pen housed 1 bitch and her litter. Bitches were fed with about $350 \mathrm{~g} /$ day with a specific dry food (Gilpa Trinkets, Gilbertson \& Page ltd, UK). Pups were fed by suckling the milk of their dam.

Bitches were administered 1 or $1 / 230 \mathrm{mg}$ Cimalgex ${ }^{\circ}$ tablet leading to an actual dose range of 1.4 to $2.6 \mathrm{mg} /$ $\mathrm{kg}$ with a target dose of $2 \mathrm{mg} / \mathrm{kg}$. Cimalgex ${ }^{\circ}$ tablets were manufactured by Vétoquinol SA. The bitches were dosed once on study day 0 about $1 \mathrm{~h}$ after birth of the last pup. The technician assisting the birth of puppies assessed if the bitch had finished whelping by manual palpation. Bitches were fed after dosing on day 0 or at most $5 \mathrm{~h}$ before dosing. Bitches were dosed again once on day 28 before the pups were suckling. The bitches were fed after dosing on day 28.

On day 0 and day 28 , all bitches were carefully observed for adverse events. Clinical assessments were carried out by a trained technician/veterinarian. Clinical assessments were performed prior to dosing and at $1.5 \mathrm{~h}$ $\pm 15 \mathrm{~min}$ post-dosing. The following parameters were assessed: behaviour, respiration, salivation/vomit, nervous signs, locomotion/musculature and faeces. When faeces were present, they were removed from the pen after each assessment. In addition, general health observations were carried out from day 0 to day 29.

On day $7( \pm 24 \mathrm{~h})$, all pups that had survived, were microchipped, weighed and examined by a veterinarian. The pups from each litter that presented any evidence of illness at the veterinary examination were not qualified for participation. All the other pups which were considered as healthy were enrolled onto the study on day 7 $( \pm 24 \mathrm{~h})$. General health observations were carried out throughout the study from day 7 to day 29 .

\section{Sampling}

Blood samples of $3 \mathrm{~mL}$ were collected post dosing (on days $0-1$ and 28-29) from the jugular vein of the bitches

Table 1 Experimental design

\begin{tabular}{llllll}
\hline \multicolumn{1}{l}{ Study days } & & & & \\
\hline Body weight & D0 & D1 & D7 & D27 & D28 \\
Clinical assessment & bitches & - & - & - & bitches, pups \\
Drug administration & bitches & - & pups & - & bitches \\
Blood sampling & bitches & - & - & - & bitches \\
Milk sampling & bitches & bitches & - & pups & bitches, pups bitches, pups \\
\hline
\end{tabular}

-: not applicable 
in tubes containing lithium heparin on the following time points: $0.5,1,2,4,6,8,10$ and $24 \mathrm{~h}$. A sample was also taken pre-treatment before whelping. Blood samples of $1 \mathrm{~mL}$ were collected (on days 28 and 29) from the jugular vein of the pups on the following time points: $1.5,4.5,8.5$ and $24 \mathrm{~h}$ after dosing the bitches or $0.5,3.5$, $7.5 \mathrm{~h}$ after suckling on day 28 and $0.5 \mathrm{~h}$ after suckling on day 29. A sample was also taken before dosing the bitch on day 27. Blood samples were collected from the pups that were confirmed to be suckling milk about $30 \mathrm{~min}$ before the first blood collection time point. A total of 4 pups per bitch $(n=24)$ was sampled. The tubes were centrifuged at $3500 \mathrm{rpm}$ for $10 \mathrm{~min}$ at $4{ }^{\circ} \mathrm{C}$. The resultant plasma collected from bitches was separated, transferred into 3 uniquely labelled clear polypropylene tubes (at least $500 \mu \mathrm{L}$ of plasma per aliquot), and placed in a $-80{ }^{\circ} \mathrm{C}$ deep freezer. There was only 1 plasma aliquot fraction for the pups.

Milk samples were collected manually from the mammary gland of the bitches into polypropylene tubes. To stimulate milk release, each bitch's nipples were gently stripped by repetitive stroking motions. Each bitch's mammary glands were either massaged or warmed with a warm cloth. About $1.1 \mathrm{~mL}$ of milk was collected on the following time points post dosing: 1, 2, 4, 8 and $24 \mathrm{~h}$. On study days 0 and 1 , a sample was taken from each animal at each time point. On study days 28 and 29 , some samples could not be taken because there was not enough milk available. On study day 28 , the first milk sample was taken just prior first suckling within 1 to $4 \mathrm{~min}$. After collection, samples were mixed gently and separated, equally transferred into 2 uniquely labelled clear polypropylene tubes (at least $500 \mu \mathrm{L}$ of milk per aliquot), and placed in a $-80{ }^{\circ} \mathrm{C}$ deep freezer.

\section{Sample analysis}

The concentration of cimicoxib in the plasma samples was determined according to a validated HPLC method described in Jeunesse et al. [20]. Briefly, cimicoxib was extracted by a solid liquid extraction process using HLB Oasis cartridges (Waters). Separation was achieved by a reverse phase column with an octadecylsilane stationary phase (Merck Lichrospher 100 RP18e (125x4) mm, $5 \mu \mathrm{m}$ ) using a guard column (Merck Lichrospher 100 RP18e $(4 \times 4) \mathrm{mm}, 5 \mu \mathrm{m})$. UV detection was performed at $242 \mathrm{~nm}$. Within-day and day-to-day coefficients of variation were less than $9 \%$ and the accuracy ranged from 94 to $103 \%$. The limit of quantification of the method was $0.01 \mu \mathrm{g} / \mathrm{mL}$. For the milk samples, the method was validated using cow milk as blank matrix. Only the extraction was altered using dichloromethane as an extracting solvent. The specificity of the method was tested against co-extracted milk impurities and against demethylated cimicoxib which is the major metabolite of cimicoxib [30]. The limit of quantification in the milk samples was $0.03 \mu \mathrm{g} / \mathrm{mL}$. Within-day and day-to-day coefficients of variation were less than $7 \%$ and the accuracy ranged from 96 to $105 \%$.

\section{Pharmacokinetic evaluation}

The individual plasma data sets were submitted to a non compartmental analysis by means of the WinNonlin ${ }^{\circ}$ software (version 5.0.1). Actual doses of cimicoxib (mg/ $\mathrm{kg}$ ) and actual blood sampling times were used for the analyses. The best-fitting slopes of the terminal phase, $\lambda z$, were computed by log-linear regression using the best adjusted R-square with at least three time points (excluding the $\mathrm{C}_{\max }$ ). Area Under the Curve (AUC) values were computed using the Linear Trapezoidal, Linear Interpolation rules. The main pharmacokinetic parameters were calculated. The following parameters obtained on D0 and on D28 were compared using paired $\mathrm{t}$ tests with a significance threshold of $5 \%: \mathrm{C}_{\max }, \mathrm{T}_{\max }$, $\mathrm{T}_{1 / 2 \lambda \mathrm{Z}}, \mathrm{AUC}_{\text {INF }}$ and Cl_F.

Only the milk data sets collected on D0 were submitted to a non compartmental analysis. There were not enough samples collected on D28 for performing a pharmacokinetic analysis. The same rules for non compartmental analysis (plasma samples) were applied to the milk samples. The last elimination slope, $\lambda z$, was not calculated because there were not enough time points.

\section{Abbreviations \\ COX: Cyclo-oxygenase; HPLC: High performance liquid chromatography; NSAID: Non steroidal anti-inflammatory drug; Rpm: Round per minute; SD: Standard deviation; UK: United Kingdom; UV: Ultra-violet.}

\section{Competing interests}

M. Schneider, F. Dron and F. Woehrlé are employees of Vétoquinol SA.The experimental test site was Charles River Preclinical Services, Ballina, Ireland and the study was sponsored by Vétoquinol SA.

\section{Author's contributions}

MS conceived of the study, drafted its design, performed the pharmacokinetic analysis, analysed the obtained results and drafted the manuscript. FD participated in the design of the study, performed the analytical work and helped to draft the manuscript. FW participated in the conception of the study, participated in the design of the study and helped to draft the manuscript. AK participated in the design of the study, coordinated the animal phase and helped to draft the manuscript. All authors read and approved the final manuscript.

\section{Acknowledgements}

We thank the technical staff of Charles River Ballina Ireland for their skilled work during the animal phase. We thank also the staff of the Bioanalysis Unit of Vétoquinol for their involvement in the analytical work.

\section{Author details}

${ }^{1}$ Vétoquinol Global Development, 70200 Lure, France. ${ }^{2}$ Crosspatrick, Killala, Co. Mayo, Ireland.

Received: 15 January 2015 Accepted: 16 July 2015

Published online: 31 July 2015 


\section{References}

1. Raffe MR, Carpenter RE. Anesthetic management of caesarean section patients. In: Tranquilli WJ, Thurmon JC, Grimm KA, editors. Lumb and Jone's Veterinary Anesthesia and Analgesia. 4th ed. Ames: Blackwell Publishing; 2007. p. 955-69.

2. Lohuis JA, van Werven T, Brand A, van Miert AS, Rohde E, Ludwig B, et al. Pharmacodynamics and pharmacokinetics of carprofen, a non-steroidal anti-inflammatory drug, in healthy cows and cows with Escherichia coli endotoxin-induced mastitis. J Vet Pharmacol Ther. 1991;14(3):219-29.

3. Malreddy PR, Coetzee JF, Kukanich B, Gehring R. Pharmacokinetics and milk secretion of gabapentin and meloxicam co-administered orally in Holstein-Friesian cows. J Vet Pharmacol Ther. 2013;36(1):14-20.

4. De Graves FJ, Riddell MG, Schumacher J. Ketoprofen concentrations in plasma and milk after intravenous administration in dairy cattle. Am J Vet Res. 1996;57(7):1031-3.

5. Anderson KL, Neff-Davis CA, Davis LE, Bass VD. Pharmacokinetics of flunixin meglumine in lactating cattle after single and multiple intramuscular and intravenous administrations. Am J Vet Res. 1990;51(9):1464-7.

6. Bergh MS, Budsberg SC. The Coxib NSAIDs: potential clinical and pharmacologic importance in veterinary medicine. J Vet Intern Med. 2005:19:633-43.

7. McDonnell NJ, Keating ML, Muchatuta NA, Pavy TJ, Paech MJ. Analgesia after caesarean delivery. Anaesth Intensive Care. 2009;37(4):539-51.

8. Bloor M, Paech M. Nonsteroidal anti-inflammatory drugs during pregnancy and the initiation of lactation. Anesth Analg. 2013;116(5):1063-75.

9. Huang YC, Tsai SK, Huang CH, Wang MH, Lin PL, Chen LK, et al. Intravenous tenoxicam reduces uterine cramps after Cesarean delivery. Can J Anaesth. 2002;49(4):384-7

10. Facchinetti F, De Pietri R, Giunchi M, Genazzani AR. Use of meclofenamic acid in gynecology and obstetrics: effects on postsurgical stress. Clin J Pain. 1991;7(Suppl 1):S60-3.

11. Rorarius MG, Suominen P, Baer GA, Romppanen O, Tuimala R. Diclofenac and ketoprofen for pain treatment after elective caesarean section. $\mathrm{Br}$ J Anaesth. 1993;70(3):293-7.

12. Munishankar B, Fettes P, Moore C, McLeod GA. A double-blind randomised controlled trial of paracetamol, diclofenac or the combination for pain relief after caesarean section. Int J Obstet Anesth. 2008;17(1):9-14.

13. Bourlert A. Diclofenac intramuscular single dose to decrease pain in post operative Caesarean section: a double blind randomized controlled trial. J Med Assoc Thai. 2005;88(1):15-9.

14. Lowder JL, Shackelford DP, Holbert D, Beste TM. A randomized, controlled trial to compare ketorolac tromethamine versus placebo after cesarean section to reduce pain and narcotic usage. Am J Obstet Gynecol. 2003;189(6):1559-62.

15. Al-Waili NS. Efficacy and safety of repeated postoperative administration of intramuscular diclofenac sodium in the treatment of post-cesarean section pain: a double-blind study. Arch Med Res. 2001;32(2):148-54.

16. Olofsson $\mathrm{Cl}$, Legeby $\mathrm{MH}$, Nygårds $\mathrm{EB}$, Ostman KM. Diclofenac in the treatment of pain after caesarean delivery. An opioid-saving strategy. Eur J Obstet Gynecol Reprod Biol. 2000;88(2):143-6.

17. Paech MJ, Salman S, llett KF, O'Halloran SJ, Muchatuta NA. Transfer of parecoxib and its primary active metabolite valdecoxib via transitional breastmilk following intravenous parecoxib use after cesarean delivery: a comparison of naive pooled data analysis and nonlinear mixed-effects modeling. Anesth Analg. 2012;114(4):837-44.

18. Kim TW, Della Rocca G, Di Salvo A, Ryschanova R, Sgorbini M, Giorgi M. Evaluation of pharmacokinetic and pharmacodynamic properties of cimicoxib in fasted and fed horses. NZ Vet J. 2015;63(2):92-7.

19. Kim TW, Della Rocca G, Di Salvo A, Owen H, Sgorbini M, Giorgi M. Pharmacokinetics of the novel cyclooxygenase 2 inhibitor cimicoxib in donkeys. J Equine Vet J. 2014;34:923-5.

20. Jeunesse EC, Schneider M, Woehrlé F, Faucher M, Lefebvre HP, Toutain P-L. Pharmacokinetic/pharmacodynamic modelling for the determination of a cimicoxib dosing regimen in the dog. BMC Veterinary Research. 2013;9(250):1-15.

21. Begg EJ. Determinants of drug transfer into human milk. In: Bennet PN, editor. Drugs and human lactation. 2nd ed. Amsterdam: Elsevier Science; 1996. p. 50-2.

22. Martinez M, Modric S. Patient variation in veterinary medicine: part I. Influence of altered physiological states. J Vet Pharmacol Ther. 2010;33:213-26.
23. Kim TW, Lebkowska-Wieruszewska B, Owen H, Yun Hl, Kowalski CJ, Giorgi M. Pharmacokinetic profiles of the novel COX-2 selective inhibitor cimicoxib in dogs. Vet J. 2014;200:77-81.

24. Oftedal OT. Lactation in the dog: milk composition and intake by puppies. J Nutr. 1984;114:803-12.

25. Jenness R. The composition of human milk. Semin Perinatol. 1979:3:225-39.

26. Jensen RG, Hagerty MM, MacMahon KE. Lipids of human milk and infant formulas: a review. Am J Clin Nutr. 1978;31:990-1016.

27. Giorgi M, Saccomanni G, Del Carlo S, Manera C, Lavy E. Pharmacokinetics of intravenous and intramuscular parecoxib in healthy Beagles. Vet J. 2012;193:246-50.

28. Alsalameh S, Burian M, Mahr G, Woodcock BG, Geisslinger G. Review article: the pharmacological properties and clinical use of valdecoxib, a new cyclo-oxygenase-2 selective inhibitor. Aliment Pharmacol Ther 2003;17:489-501.

29. Huggins RA, Deavers S, Smith EL. Growth in Beagles: changes in body weight, plasma volume, and venous hematocrit. Pediat Res. 1971;5:193-8.

30. Anonymous. EMEAN/C/000162. In: Cimalgex: EPAR - Product Information, Annex I - Summary of product characteristics. London: European Medicines Agency, Veterinary Medicines; 2011.

\section{Submit your next manuscript to BioMed Central and take full advantage of:}

- Convenient online submission

- Thorough peer review

- No space constraints or color figure charges

- Immediate publication on acceptance

- Inclusion in PubMed, CAS, Scopus and Google Scholar

- Research which is freely available for redistribution 